\title{
Contexto y propuesta del radio de acción de la familia
}

\author{
Yván Balabarca Cardenas ${ }^{1 \mathrm{a}}$ \\ Universidad Peruana Unión ${ }^{1}$
}

Orcid ID: https://orcid.org/0000-0002-2955-2816¹

Recibido: 21 de noviembre de 2017

Aceptado: 01 de enero de 2018

\section{Resumen}

Este artículo pretende dar una revisión a los macro movimientos sociales que impactaron a la familia en el siglo XIX y XX; la adaptación de la familia hacia estas tendencias; y, la propuesta del radio de acción de la familia adventista en esta época.

Palabras clave: familia, educación, megatendencias, filosofía, economía

\section{Context and proposal of the scope of family action}

\begin{abstract}
This article aims to give a review of the macro social movements that impacted the family in the nineteenth and twentieth centuries; the adaptation of the family to these tendencies; and, the proposal of the scope of action of the Adventist family at this time.
\end{abstract}

Key-words: family, education, megatrends, philosophy, economy

\section{Introducción}

El rol de la familia es gravitante en el quehacer humano en todas las sociedades. Los estudios comenzaron a ver a la familia como un constructo que ha avanzado a lo largo de diversas época o etapas que han impactado en los hogares. La familia se ha ido 
adaptando a estos cambios; sin embargo, la familia adventista debe asumir algunos paradigmas y roles para permanecer y desarrollarse en sus respectivos contextos.

\section{Revisión}

Por siglos las familias han sido nucleares, no tanto en sociedades, sino en solidaridades, para luego convertirse hoy en día en sociedades de poblaciones anónimas, en que las personas ya no se conocen (Bel, 2000). ${ }^{\text {b }}$ Era sabido que los padres tenían sus talleres, tiendas o trabajos en el mismo hogar, o muy cerca de donde vivían y que la cultura era cerrar los negocios para poder ir a disfrutar del almuerzo y la cena con la familia; en este hecho, no solo se enseñaba a las nuevas generaciones una manera de ganarse la vida, sino la identidad familiar. ${ }^{\mathrm{c}}$

Los mejores maestros eran los padres, quienes atendían las necesidades de tipo académico de sus hijos que tenían la intención de formar a los niños para la felicidad que giraba consistentemente en la cultura (moral) y cosmovisión (ética) de los padres.

Pero la cultura y las mentes curiosas de los seres humanos, quienes desde el renacimiento desarrollaron en libertad diferentes esfuerzos innovadores en diversos campos del conocimiento, encontraron que facilitaban y enriquecían la vida del género humano.

Estos conocimientos fueron aquilatados por diversos hombres de negocios quienes organizaron sus haciendas en fábricas, dando inicio en el siglo XIX a la primera revolución industrial, a la que las familias de campesinos y artesanos se integraron o tuvieron que hacerlo (Camarena, 2001), ${ }^{\mathrm{d}}$ para poder sobrevivir.

Marín (2002) consideró que la revolución industrial trajo adelanto en los campos de la agricultura, el comercio, el transporte y demografía. Esta revolución industrial

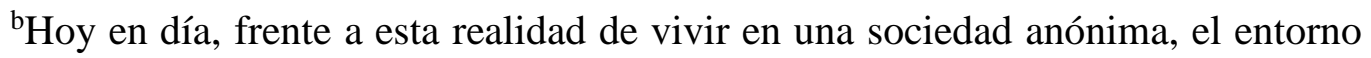
familiar se ha convertido en un lugar donde el ser humano se protege de la mirada de los demás, a través del derecho de elegir con mayor libertad tu tipo de vida, y convirtiéndola en su espacio personal y privado.

${ }^{c}$ Esto se hace evidente al ver los apellidos que se conocen, como Molinero, Guerrero, Zapatero, Jurado, Vaquero, o aun en otras leguas como Fisher (pescador), Ferraro (herrero) o Kaminski (cantero en polaco); es decir, con la enseñanza de la profesión, se heredaba toda una identidad familiar. En Génesis, capítulo 4 encontramos referencias a oficios que son heredados de los padres. Esto podría reforzar la idea planteada.

${ }^{\mathrm{d}}$ Una vez establecidas las fábricas, se constituyeron como centros donde las familias pudiesen ser integradas al trabajo. Poco a poco, el padre fue sustituido por un capataz, tutor o maestro en la obra a la que los niños eran invitados a trabajar. 
apuntaló la presencia de los Estados Unidos y de Inglaterra como potencias industriales de su época y provocó no solo una revolución en la industria sino un cambio en el pensamiento, ya que rompió los valores tradicionales por uno más racionalista, y añado, mercantilista.

Fueron décadas en las que muchas familias se desunieron, haciendo que los padres fueran a buscar mejores opciones a las fábricas, y los niños quedaran con las mamás en sus casas, para que pronto las mismas mujeres y niños pasaran a engrosar las filas de la población económicamente activa. El proceso de tránsito de los padres hacia las líneas de producción fue cada vez más grande (Fernández, Fernández y Alegre, 2007).

Años después, a partir de la década de los 40 del siglo XIX se inició la segunda revolución industrial que duró hasta las primeras décadas del Siglo XX. Si en la primera revolución el móvil fue el vapor, en la segunda fueron el petróleo y la electricidad los marcos de desarrollo, que impulsaron la hegemonía del capital financiero, representado en las poderosas administraciones. Esto ayudó a que tanto empresarios y bancos monopolizaran el capital “dinero” (Quesada, 1993).

Así, Savchuk (2015) recuerda que surgieron familias de industriales como los Rockefeller, Carnegie, Mellon, Vandervilt, entre otras. Estas familias, a fin de poder dar fuerza y alcance a sus operaciones, se organizaron para dar estabilidad a sus empresas; incluso se cambió el patrón de oro por el patrón moneda para facilitar el intercambio de divisas en los países (Sachs y Larraín, 2002).

En otra parte del mundo, pensadores como Engels y Marx miraban como un vicio este sistema conocido como "capitalismo", y propusieron que el capital no estaba en los poderosos sino en los trabajadores. Se estaba generando la corriente comunista, marxista (Azuela, 1991).

Mientras tanto, los padres, con la liberación femenina las mujeres, luchando por tener los mismos privilegios económicos de los varones (Galué, 2005), terminaron por lograr que los niños también trabajen y mueran en estas primitivas fábricas (Ortega, 2006), por lo que desde temprano en el siglo XIX se inició la educación pública en Estados Unidos (Rury, 2005). Pienso yo como una guardería y a la vez como una estrategia de preparación para el sistema febril.

Décadas después aparecieron los colegios industriales para preparar mejor a los alumnos a fin de insertarlos en el medio laboral competitivo que se estaba generando. 
A fin de poder comprar más y estar al día con los que la industria producía, los padres aprendieron a trabajar más. Unos en trabajos que ganaban más que otros, por lo que se iniciaron las protestas y batallas por mejores ingresos y remuneraciones.

La familia se terminó adaptando a esto. Los hijos con menos tiempo de ver a sus padres, y los padres con cada vez más necesidades económicas para cubrir sus propias necesidades y de los hijos.

A esto sumemos la llegada de nuevas corrientes en el siglo XIX.

El evolucionismo. Gracias al sistema del que dotó Darwin a la postura Lamarckina, la teoría evolucionista causó un impacto. El origen de las especies (1859) impulsó esta tendencia (Flori y Rasolofomasoandro, 2000), hasta el día de hoy. Así, el ser humano no es un ente que tiene un futuro glorioso, sino que es un animal que debe ser productivo, y que vive para el hoy. Debía estudiar porque la vida vendría a ser la sobrevivencia del más fuerte o más adaptado.

La psicología o mesmerismo. Fueron las posturas psicológicas de Antón Mesmer (1734 - 1815), quien inició el que hacer de la hipnosis para curar conductas anormales. Se volvió muy famoso en París. Su postura se llamó "magnetismo animal” y se trataba de intentar curar a los seres humanos revitalizando solamente sus propios cuerpos (Sala y Hintzmann, 2005). De este modo, la salud no estaba en un este exterior, sino en las propias "energías vitales" de cada individuo (Otra forma de expresar que Dios no era necesario).

La liberación femenina. González, Ortiz y Pérez (2016, p. 2541) manifiestan:

El espiritismo, al igual que el anarquismo, reivindicó la igualdad absoluta entre los sexos y la liberación de la mujer. Algunas publicaciones espiritistas, que condenaban la subordinación femenina a manos de maridos y curas opresores, tuvieron u papel destacado en los inicios del feminismo contemporáneo. En el caso de España destaca la revista espiritista La Luz del Porvenir $(1879$ - 1900), semanario para mujeres escritos exclusivamente por mujeres, dirigido por Amalia Domingo Soler, la divulgadora mundial más importante de espiritismo en lengua castellana del siglo XIX.

De esta cita, encontramos que el siglo XIX también nos legó la filosofía libertaria de las damas (y que en algunos países fue auspiciada por los postulados espiritistas) lo que contribuyó en alejar a la mujer de su familia. No pienso que haya problema en que la mujer ejerza sus derechos; el problema está en el pensamiento de: "No necesitamos al hombre para nada". Esto tarde o temprano desestabiliza el hogar. 
Además, la industria nos proveyó una serie de procesos que impulsó el consumo, mismos que se fueron convirtiendo en a una nueva ideología, la del consumismo, con sus propios templos de la impersonalidad (centros comerciales) (Lázaro y Mayoral, 2005).

Todo esto fue reforzando la idea de una lucha por ser mejor y tener más. A esto añádase la realidad de que la familia hoy en día sigue formando a las personas con la finalidad de que estas pasen a ser generadores de servicios o productores, así como consumidores para que esta cadena de consumo se siga desarrollando, haciendo que las mega corporaciones sean cada vez más fuertes.

¿La familia está cumpliendo su rol bíblico de preparar ciudadanos para el reino de los cielos? ¿Nuestro medio social ayuda a que esto sea una realidad?

Pues la respuesta a esta pregunta es que la familia está haciendo todos sus esfuerzos para preparar ciudadanos para el reino de Dios (Davidson e Iparraguirre, 2016), sin embargo, el medio social ayuda cada vez menos.

La familia tiene los siguientes aliados:

Los colegios. Las instituciones educativas adventista hacen bien en enseñar las ciencias y las artes en los niños, pero su principal fin es el de ayudar a las familias a que estas puedan ejercer en ambos entornos, una influencia que los ayude a los muchachos a desarrollarse como candidatos para vivir con Dios.

Las iglesias. Desarrollar su posición de lugares de Adoración es indispensable. ¿Las iglesias son un lugar de formación? O ¿son un lugar de expresión de la fe? Estas preguntas pueden generar un amplio debate, sin embargo, es necesario que veamos a la iglesia como una extensión del hogar, como un medio social en el que las familias se unan con otras que tienen las mismas preocupaciones por hacer que sus hijos y los padres mismos refuercen sus intenciones de ser personas cristianas.

Los hogares. Quizás debiéramos despertar a una realidad. Somos hogares cristianos. Es cierto que debemos buscar vivir con dignidad, pero también debemos aprender a sacar el mejor partido a las cosas, para no caer en la cadena de consumo.

Estas tres entidades deben trabajar juntas, como marcos de expresión de la misma unidad familiar. La familia expresándose en el hogar, en la escuela, y en las iglesias.

Desestabilizar el hogar fue uno de los mayores objetivos que tuvo el diablo, que quiso hacer del jardín del Edén su cuartel general, desde donde liderar su rebelión cósmica. El jardín del edén era el punto de encuentro entre el ser humano y Dios. Era el hogar que Dios había provisto para el ser humano y lo que el diablo quiso fue ingresar al lugar físico de reunión (White, 2013). La agenda del enemigo no ha cambiado. 
Logró introducirse en la relación hombre - Dios, luego intentó establecer su cuartel general en el Edén, pero Dios no lo permitió: “Echó, pues, fuera al hombre, y puso al oriente del huerto de Edén querubines, y una espada encendida que se revolvía por todos lados, para guardar el camino del árbol de la vida" (Génesis 3:24).

Luego se introdujo en el corazón de los antediluvianos.

Mas, ¿quién reconoce las advertencias dadas por las señales de los tiempos que se suceden con tanta rapidez? ¿Qué impresión hacen a los mundanos? ¿Qué cambio podemos ver en su actitud? Su actitud no se diferencia de la de los antediluvianos. Absortos en sus negocios y en los deleites mundanos, los contemporáneos de Noé "no conocieron hasta que vino el diluvio y llevó a todos". Mateo 24:39. Las advertencias celestiales les fueron dirigidas, pero rehusaron escuchar. Asimismo, hoy el mundo, sin prestar atención alguna a las amonestaciones de Dios, se precipita hacia la ruina eterna" (White, 1997).

Sabemos por historia bíblica que los descendientes tanto de Noé como de Abraham terminaron dejando los caminos señalados por la revelación bíblica. Desde el siglo XIX, se está tendiendo todo lo necesario para que, por la vía económica, se pueda forzar a la familia a estar lo suficientemente debilitada. Así, existen múltiples mega tendencias económicas, empresariales, psicológicas, políticas, sociales, filosóficas; y todas humanistas, centradas en el hombre y su aparente potencial; y a la vez, vemos como el mismo hombre se corrompe a sí mismo, y a su ecosistema.

Todo está dado como para que la familia crezca desestabilizada, multi problemática, y disfuncional. Paso a dar algunas recomendaciones.

\section{Conclusiones}

En estas épocas, propongo seis ideas que han de ser implementadas.

1. Las instituciones educativas escolares no deben trabajar solo en la formación de los alumnos. Deben trabajar también en la formación de los hombres y mujeres adultos. Negar esto es negar los principios andrológicos que se vienen desarrollando. El carácter puede y debe ser transformado, con la participación de maestros. Las instituciones educativas deben educar a los padres en temas de presupuesto, dialogo, paternidad.

2. Las iglesias deben ser lugares de encuentro familiar, para crecer en el conocimiento del Dios verdadero. Deben ser lugares de instrucción en el que las familias encuentres orientación para su vida espiritual.

3. Las instituciones educativas universitarias deben ayudar a los jóvenes a terminar de formar los hábitos misionales a la par de sus vidas formativas laborales. 
4. Nuestro énfasis debe ser el reforzar en la mente de los actores del hogar la presencia de un Dios amoroso, que está dispuesto a utilizarlos para salvar a la mayor cantidad de personas. Esa salvación no es etérea, sino evidente a través de un mejor estilo de vida (los 8 remedios naturales).

5. Necesitamos articular mejor nuestros esfuerzos en base a una misión y visión que conlleve a estos tres actores a asumir su parte en el proceso de salvación de los seres humanos.

6. Recordemos que los seres humanos no crecen de la nada, sino de los hogares. Por lo tanto, cada una de las instituciones debe asumir su rol en el proceso formativo de todos los que componen la familia.

\section{Referencias.}

Azuela Güitrón, Mariano (1991). Derecho, sociedad y estado. D.F., México: Universidad Iberoamericana Departamento de Derecho, 197.

Bel Bravo, María Antonia (2000). La familia en la historia: propuestas para su estudio desde la 'nueva' historia cultural. Madrid: Ediciones Encuentro, S.A. 12.

Davidson, R. y Iparraguirre, J. (2016). El matrimonio, ¿todavía importa?: Una evaluación de la convivencia a la luz de la Biblia. Revista Apuntes Universitarios. Vol. VI, Nro. 1, 149 - 159.

Camarena Ocampo, Mario (2001). Jornaleros, tejedores y obreros: historia social de los trabajadores textiles de San Ángel (1850 - 1930). México, D.F.: Plaza y Valdés. 60.

Fernández, C., Fernández, P. y Alegre, L. (2007). Educación para la ciudadanía, democracia, capitalismo y estado de derecho. Madrid: Lavel S. A. 152.

Flori, Jean, y Rasolofomasoandro, H. (2000). En busca de los orígenes: ¿evolución o creación?. Madrid: Safeliz, 154.

Galué, Carmen (2012). He aquí una mujer. (USA: Xulon Press, 2012). 39, 40;

Silva A., y, Mata, L. (2005). La llamada revolución industrial. Caracas: Universidad Católica Andrés Bello. 95.

González, D., Ortiz, M., Pérez, J. (2016). La historia, lost in translation? Actas del XIII Congreso de la Asociación de Historia Contemporánea. Castilla - La Mancha: Universidad de Castilla - La Mancha. 2541.

Hahn, Scott (2011). Muchos son los llamados sobre la grandeza del sacerdocio. Madrid: Rialp. 46

Lázaro, I. y Mayoral, I. (2005). Infancia, publicidad y consumo: Facultad de Derecho, 18 y 19 de noviembre de 2004. Madrid: Universidad Pontificia Comillas. 308. 
Marín, Lucas A. (1992). Sociología de la empresa. Madrid: Ibérico Europea de Ediciones S. A. 92.

Ortega Torres, Justo (2006). Bajo rendimiento escolar: bases emocionales de su origen y vías afectivas para su tratamiento. Madrid: Incipit Editores. 368.

Quesada Monge, Rodrigo (1993). El siglo de los totalitarismos, 1871-1991: ensayo sobre historia contemporánea (de la guerra Franco-Prusiana a la guerra del Golfo Périsco). San José, Costa Rica: Editorial Universidad Estatal a Distancia. 19, 20.

Urban, R. (2005). Education in the United State, a historical reader. New York: Plagrave Macmillan. 25.

Sachs, Jeffrey D., y Larraín F. (2002). Macroeconomía en la economía global. Argentina: Prentice-Hall Hispanoamericana. 252.

Sala Rios, M. y Hintzmann C. (2005). Introducció a l'economia. Barcelona: UOC. 90.

Savchuk, K. (2015). Las 15 fortunas familiares más antiguas de Estados Unidos. Forbes México. Recuperado: https://www.forbes.com.mx/las-15-fortunas-familiaresmas-antiguas-de-estados-unidos/

White, Elena (1997). Consejos para la iglesia: manual de creencias doctrinales y vida cristiana. Buenos Aires, Argentina: Asociación Casa Editora Sudamericana. 68.

White, Elena (2013). No deserto da tentação. Tatuí, SP: Casa Publicadora Brasileira, 13. 